This is the peer reviewed version of the following article: Wang, B. and Fancey, K. S. (2017), Application of time-stress superposition to viscoelastic behavior of polyamide 6,6 fiber and its "true" elastic modulus. J. Appl. Polym. Sci., 134, 44971 which has been published in final form at http://dx.doi.org/10.1002/app.44971. This article may be used for non-commercial purposes in accordance With Wiley Terms and Conditions for self-archiving.

Journal of Applied Polymer Science (2017), DOI: 10.1002/app.44971

\title{
Application of time-stress superposition to viscoelastic behavior of polyamide 6,6 fiber and its 'true' elastic modulus
}

\author{
Bing Wang, Kevin S. Fancey \\ School of Engineering, University of Hull, HU6 7RX, UK \\ Correspondence to: K.S. Fancey (Email: k.s.fancey@hull.ac.uk)
}

\begin{abstract}
The viscoelastic behavior of semi-crystalline polyamide 6,6 fiber is exploited in viscoelastically prestressed polymeric matrix composites. To understand better the underlying prestress mechanisms, strain-time performance of the fiber material is investigated in this work, under high creep stress values (330-665 MPa). A latch-based Weibull model enables prediction of the 'true' elastic modulus through instantaneous deformation from the creep-recovery data, giving $4.6 \pm 0.4$ GPa. The fiber shows approximate linear viscoelastic characteristics, so that the time-stress superposition principle (TSSP) can be implemented, with a linear relationship between the stress shift factor and applied stress. The resulting master creep curve enables creep behavior at $330 \mathrm{MPa}$ to be predicted over a large timescale, thus creep at $590 \mathrm{MPa}$ for $24 \mathrm{~h}$ would be equivalent to a $330 \mathrm{MPa}$ creep stress for $\sim 5200$ years. Similarly, the TSSP is applied to the resulting recovery data, to obtain a master recovery curve. This is equivalent to load removal in the master creep curve, in which the yarns would have been subjected to $330 \mathrm{MPa}$ creep stress for $\sim 4.56 \times 10^{7} \mathrm{~h}$. Since our work involves high stress values, the findings may be of interest to those involved with long-term load-bearing applications using polyamide materials.
\end{abstract}

\section{INTRODUCTION}

Viscoelastic behavior can have a profound influence on the mechanical performance of polymeric fibers. ${ }^{1}$ Of particular interest, is polyamide 6,6 fiber, as this has become the most established reinforcement in the development of viscoelastically prestressed polymeric matrix composites (VPPMCs). The first VPPMCs to be successfully demonstrated utilized polyamide 6,6 fiber ${ }^{2}$ and their development has progressed, leading to, for example, commingled polyamide 6,6-aramid fiber VPPMCs for enhanced mechanical performance. ${ }^{3}$ Most recently, polyamide 6,6 fiber has been used to produce the first bistable morphing structure based on VPPMC principles, and this may provide opportunities to develop morphing aerofoils for aerospace and other applications. ${ }^{4}$ Thus it is the fiber material under investigation in this paper. The fibers are considered to store mechanical energy during tensile creep, which is progressively released through viscoelastic recovery following load removal. When constrained in a matrix, contraction of these fibers can impart compressive stresses into the matrix, thereby improving the mechanical properties of the resulting VPPMC. ${ }^{5}$ In a recent study, VPPMCs were successfully produced from polyamide 6,6 fibers subjected to higher creep stress conditions, as this reduced the processing time. ${ }^{6}$ Clearly, these first steps towards process optimization lead to a requirement for further understanding of the underlying mechanisms.

Therefore, the aim of the current study is to evaluate the elastic and long-term viscoelastic behavior of polyamide 6,6 fiber under high stress conditions. 
Research into the morphological characteristics of semi-crystalline fibers has resulted in models for different fibrous structures, ${ }^{7}$ i.e. the two-phase Microfibrillar model, ${ }^{8-11}$ and the three-phase Swisscheese model. ${ }^{12}$ Though it is still inconclusive on a microstructural scale, the behavior of polyamide fibers can be explained by the Swiss-cheese model as first proposed by Prevorsek. ${ }^{13}, 14$ Briefly, the semi-crystalline polyamide fiber is considered to consist of three phases, i.e. crystalline regions (anisotropic), isotropic amorphous regions and orientated amorphous domains. Orientation occurs during the drawing process and is associated with re-crystallization, ${ }^{8}$ i.e. phase transaction. Therefore, differences in the fiber forming process could induce discrepancies on the microstructural scale, and affect mechanical properties. For example, polyamide 6,6 as a fiber material, is shown to exhibit linear viscoelasticity below $50 \mathrm{MPa}$ creep stress, ${ }^{15,16}$ however, as a matrix material, nonlinear viscoelastic characteristics have been demonstrated under creep conditions of up to $40 \mathrm{MPa} .{ }^{17}$

The time-dependent properties of polymeric materials can be represented through a spring-dashpot latch model. ${ }^{18}$ The creep, recovery and stress relaxation behavior of a polymeric material correlate well with Weibull (stretched exponential) functions. For viscoelastic materials, tensile stress in tensile testing can produce elastic and viscoelastic deformation. Therefore, to obtain the 'true' elastic modulus of a viscoelastic solid, the stress-strain relationship from elasticity only is required, and clearly, this is not possible from routine tests as no load can be physically applied instantaneously. ${ }^{1}$ In general, the stress-strain characteristics of polymeric materials are highly dependent on strain rate and environmental conditions. ${ }^{19}$ The Young's modulus of polyamide 6,6 materials can therefore be strongly influenced by strain rate and temperature, ${ }^{20,21}$ with values ranging from 2.8 to $4.9 \mathrm{GPa}^{22,23}$ An alternative approach is to exploit the Weibull model as this can fit well to creep strain data, ${ }^{16,18}$ which allows the prediction of purely elastic strain, $\varepsilon_{i}$, under different stress levels. Thus, creep tests of polyamide 6,6 fiber, under a range of applied stress values, could provide an actual elastic stressstrain curve, which enables the 'true' elastic modulus of the viscoelastic material to be determined.

The viscoelastic behavior of polymers is considered to possess an intrinsic time that can be influenced by many factors. ${ }^{24-26}$ To date, the influence of temperature, stress, strain and moisture content on the intrinsic time of viscoelastic materials have been intensively investigated in terms of tensile creep, ${ }^{15}$, ${ }^{27-31}$ flexural creep, ${ }^{32}$ dynamic tensile modulus ${ }^{33,34}$ and stress relaxation. ${ }^{33,35,36}$ Since increased load, temperature and moisture content could all shift the polymeric creep curves to shorter timescales, ${ }^{37}$ superposition principles can be used to shift different temperatures, humidity and stress levels from some convenient short-term scales to construct a master curve with a much wider timescale at a constant condition. This allows prediction of the time-dependent viscoelastic response of materials. For polyamide 6,6 fiber, its viscoelastic creep properties have been investigated by Howard and Williams ${ }^{15}$ using low stresses (10 MPa, $35 \mathrm{MPa}, 50 \mathrm{MPa}$ ) and later by Fancey ${ }^{38,39}$ using $282 \mathrm{MPa}$, $342 \mathrm{MPa}$ and $401 \mathrm{MPa}$ creep stress values. In this research, large creep stress values ranging from $330 \mathrm{MPa}$ to $665 \mathrm{MPa}$ were adopted. The time-stress superposition principle (TSSP) was applied to predict long-term viscoelasticity. Though the TSSP has been reported to fit well to the creep behavior of unoriented polyamide 6,6 monofilaments using low creep stress values $(<50 \mathrm{MPa})^{37}$, its applicability to oriented polyamide 6,6 fiber is still unknown.

\section{EXPERIMENTAL}

\section{Materials}

The fiber material used in this work was polyamide 6,6, supplied by Ogden Fibers Ltd, UK. This was a continuous untwisted multifilament yarn, with 140 filaments, $26 \mu \mathrm{m}$ filament diameter and 94 tex. 
The fiber breaking strength was 700-900 MPa. ${ }^{39}$ The degree of crystallinity, from X-ray diffraction, was $51 \%$ in as-received condition and $53 \%$ following annealing. ${ }^{40}$

\section{Creep and recovery tests}

Creep and recovery measurements followed previously described procedures. ${ }^{41}$ Briefly, the polyamide yarns were first subjected to annealing $\left(150^{\circ} \mathrm{C}\right.$ for $\left.30 \mathrm{~min}\right)$. This was essential to remove manufacturing-induced residual stresses. ${ }^{39,42,43}$ Following annealing, at least $0.5 \mathrm{~h}$ was allowed to elapse for the yarns to regain equilibrium moisture content before performing the creep tests. A vertical stretching rig was used for testing. Annealed yarn (typically $\sim 1300 \mathrm{~mm}$ in length) was folded and attached between upper and lower bobbins; the lower bobbin was fixed to a counterbalanced platform to accommodate various creep loads. A period of $24 \mathrm{~h}$ was adopted for all creep runs. Creep strain was monitored by measuring the distance between two inked marks on the yarn (300-400 mm apart), using a digital cursor with a precision of $\pm 0.01 \mathrm{~mm}$. For repeatability, three samples of annealed yarn were subjected to creep at each of the designated stress values, and recovery strain was subsequently monitored following the creep load removal. All strain readings were taken under ambient conditions of $20.0-21.5^{\circ} \mathrm{C}$ and $30-40 \% \mathrm{RH}$. A commercially available software package (CurveExpert 1.4) was used to fit the Weibull-based equations to the strain-time data, to provide the equation parameters and correlation coefficients.

The first steps towards VPPMC process optimization involved an evaluation of creep-recovery behavior at stress values of $330 \mathrm{MPa}, 460 \mathrm{MPa}$ and $590 \mathrm{MPa}{ }^{6}$ Examination of fibers by scanning electron microscopy following the maximum loading condition (590 MPa for $24 \mathrm{~h}$ ) revealed no fiber damage. In the current work, three more creep stress conditions (395 MPa, $525 \mathrm{MPa}$ and $665 \mathrm{MPa}$ ) were studied to determine the fiber elastic and long-term viscoelastic characteristics.

\section{MODELING OF VISCOELASTIC BEHAVIOR}

The creep-strain curve for a polymer may consist of three stages, as represented in Figure 1. An initial, effectively time-independent elongation $\varepsilon_{\mathrm{i}}$ (mainly elastic deformation), is produced once a creep load is applied. In Stage I, the creep rate decreases rapidly with time, which can be attributed to molecular chain slippage and reorientation. ${ }^{44}$ After a certain period, Stage II follows, in which the rate reaches a steady-state minimum value, and usually lasts for a relatively long period. Finally, Stage III occurs with a rapid increase in creep rate beyond the yield creep strain, ultimately leading to creep fracture of the material. ${ }^{1,4-46}$ It should be noted that Figure 1 is somewhat idealized and some materials may only possess partial stages of the curve. This depends on microstructure. ${ }^{1}$ The creepstrain behavior in Stages I and II (below the creep yield strain) can be represented by a Weibull function, in which the creep strain $\varepsilon_{\text {ctot }}(t)$ at time $t$ under a constant stress, follows: ${ }^{16}$

$$
\varepsilon_{\text {ctot }}(t)=\varepsilon_{\mathrm{i}}+\varepsilon_{\mathrm{c}}\left[1-\exp \left(-\left(\frac{t}{\eta_{\mathrm{c}}}\right)^{\beta_{\mathrm{c}}}\right)\right]
$$

where $\varepsilon_{1}$ is the instantaneous strain from initial application of the stress; the $\varepsilon_{\mathrm{c}}$ function is the timedependent creep strain, with $\eta_{\mathrm{c}}$ and $\beta_{\mathrm{c}}$ as the characteristic life and shape parameter respectively.

The dashed line in Figure 1 shows the recovery strain-time curve after releasing the creep load at $t_{1}$. Following load removal, the polymeric sample undergoes recovery, elastically and viscoelastically. Elastic recovery, as represented by $\varepsilon_{\mathrm{e}}$, occurs immediately, while viscoelastic (time-dependent) 
recovery is represented by the $\mathcal{E}_{\mathrm{r}}$ function. Following elastic recovery, the remaining recovery strain, $\mathcal{E}_{\text {rvis }}(t)$ is: ${ }^{16}$

$$
\varepsilon_{\text {rvis }}(t)=\varepsilon_{\mathrm{r}}\left[\exp \left(-\left(\frac{t}{\eta_{\mathrm{r}}}\right)^{\beta_{\mathrm{r}}}\right)\right]+\varepsilon_{\mathrm{f}}
$$

where, $\eta_{\mathrm{r}}$ and $\beta_{\mathrm{r}}$ are the Weibull parameters analogous to Eq. (1); $\varepsilon_{\mathrm{f}}$ is the (non-recoverable) strain from viscous flow.

Figure 2 shows schematically, the stress-strain behavior of elastic and viscoelastic materials at two fixed values of elapsed time $t^{\prime}$ and $t^{\prime \prime}$ during creep tests. For a perfectly elastic material, stress is directly proportional to strain, giving a constant gradient, i.e. the Young's modulus. For a viscoelastic material, the stress is a function of strain and time, and the material is considered to be linear viscoelastic when stress is directly proportional to the strain with gradients that reduce for increasing values of elapsed time. ${ }^{46,47}$ Thus, a shift factor $\alpha_{c}$ can be defined mathematically and follows:

$$
\alpha_{\mathrm{c}}=\frac{\varepsilon_{\mathrm{ctot}}\left(\sigma_{0}, t\right)}{\varepsilon_{\mathrm{ctot}}\left(\sigma_{1}, t\right)}
$$

where $\sigma_{0}$ is the reference stress and $\sigma_{0}<\sigma_{1}$. Therefore, a higher creep strain (under stress value $\sigma_{1}$ ) could be shifted to $\varepsilon_{\text {ctot }}\left(\sigma_{0}, t\right)$ through $\alpha_{\mathrm{c}}$.

Analogous to the linear viscoelastic behavior in creep, is $\alpha_{\mathrm{r}}$, which is defined as the recovery shift factor:

$$
\alpha_{\mathrm{r}}=\frac{\varepsilon_{\mathrm{rvis}}\left(\sigma_{0}, t\right)}{\varepsilon_{\mathrm{rvis}}\left(\sigma_{1}, t\right)}
$$

Thus, recovery strain under $\sigma_{1}\left(>\sigma_{0}\right)$ can be shifted to $\varepsilon_{\text {rvis }}\left(\sigma_{0}, t\right)$ through $\alpha_{\mathrm{r}}$ for a linear viscoelastic material.

\section{TIME-STRESS SUPERPOSITION PRINCIPLE}

The TSSP can be developed to predict the viscoelastic response of a material over a large timescale. Superposition was originally established between time and temperature, to form the well-known timetemperature superposition principle (TTSP). ${ }^{48}$ This is based on the Doolittle formula, in which the viscosity is shown to be a function of free volume. ${ }^{49} \mathrm{O}^{\text {'Shaughnessy }}{ }^{50}$ first demonstrated the existence of time-stress correspondence through experimental study. Ferry and Stratton ${ }^{51}$ found that the free volume interpretation of the dependence of viscosity could be extended to molecular concentration, pressure, and tensile strain, and this gives the basis for the TSSP. For polymers with a Poisson's ratio $\mu$ less than 0.5 , the increase in fractional free volume $f$ from stress-induced strain $\varepsilon$ can be given by: ${ }^{51}$

$$
\partial f / \partial \varepsilon=\left(\beta_{f} / \beta\right)(1 / v)(\partial v / \partial \varepsilon)
$$

where $\beta$ is the compressibility coefficient; $\beta_{f}$ is the compressibility of the free volume; $v$ is the specific volume. For a small strain change $\Delta \varepsilon$, the strain shift factor, $\alpha_{\varepsilon}$, can be defined as: 


$$
\log \alpha_{\varepsilon}=-\frac{\left[1 /\left(2.303 f_{0}\right)\right] \Delta \varepsilon}{f_{0} /\left(\beta_{f} / \beta\right)(1-2 \mu)+\Delta \varepsilon}
$$

where, $f_{0}$ is the free volume fraction at reference strain. Since strain $\varepsilon=\sigma / E$, where $\sigma$ is the stress applied to the polymer and $E$ is the elastic modulus, and assuming $\alpha_{\sigma}$ is the stress shift factor, then:

$$
\log \alpha_{\sigma}=-\frac{\left[1 /\left(2.303 f_{0}\right)\right]\left(\sigma-\sigma_{0}\right)}{E f_{0} /\left(\beta_{f} / \beta\right)(1-2 \mu)+\left(\sigma-\sigma_{0}\right)}
$$

When $C_{3}=1 /\left(2.303 f_{0}\right)$ and $C_{4}=E f_{0} /\left(\beta_{f} / \beta\right)(1-2 \mu)$, Eq. (7) becomes identical to the well-known WilliamsLandel-Ferry (WLF) equation, i.e:

$$
\log \alpha_{\sigma}=-\frac{C_{3}\left(\sigma-\sigma_{0}\right)}{C_{4}+\left(\sigma-\sigma_{0}\right)}
$$

Therefore, the TSSP shares the same basis as the TTSP, i.e. the free volume theory. A successful transformation of the $\log \alpha_{\mathrm{T}}$ (temperature shift factor) values from creep ${ }^{15}$ and stress relaxation ${ }^{35}$ have been reported in relation to predicting the long-term behavior of recovery in polyamide 6,6 fiber $^{39}$ and the (associated) impact toughness in polyamide fiber-based VPPMCs. ${ }^{39,43,52}$ Therefore, in addition to creep, the applicability of $\alpha_{\sigma}$ to recovery behavior was also evaluated in the current work.

\section{RESULTS AND DISCUSSION}

\section{Creep and recovery}

Figure 3(a) shows the creep strain-time performance, together with the curve-fits using Eq. (1). The corresponding equation parameter values are listed in Table 1. Despite data scatter, the three runs at each creep stress demonstrate good repeatability. As the polyamide 6,6 fiber is multifilament yarn, the scatter in data points is primarily due to the inconsistency in physically locating the edges of inked marks during strain measurements. The creep strain clearly increases with applied stress, which in terms of a mechanical latch-based spring and dashpot model, may result from more time-dependent latch elements being activated under higher creep stresses. ${ }^{16}$

The resulting recovery data from the $24 \mathrm{~h}$ creep runs in Figure 3(a) are shown in Figure 3(b), the strain data being monitored up to approximately two years in real time. Clearly, there is greater scatter with the recovery strain data in Figure 3(b), compared with the creep strain data in Figure 3(a). This is attributed to the yarns being held in a high state of tension for the latter case, which facilitated measurements. The corresponding parameter values from Eq. (2) are shown in Table 1. It is worth noting that the value for $\mathcal{E}_{\mathrm{f}}$ from creep at the highest stress $(590 \mathrm{MPa})$ is less than $10^{-4} \%$; i.e. viscous flow effects are predicted to be negligible. This indicates that most of the available recovery is viscoelastic, which, for polyamide fiber VPPMCs, implies that the viscoelastic prestressing mechanism would not be limited by an eventual contribution from viscous flow. This is in accordance with previous work. , $^{6,39}, 52$

For a particular stress value, the instantaneous elastic recovery $\varepsilon_{\mathrm{e}}$, can be determined from the difference between the total strain at the end of the $24 \mathrm{~h}$ creep test, and the initial value of recovery strain predicted from Eq. (2). ${ }^{16}$ The predicted $\varepsilon_{\mathrm{e}}$ values are shown in Figure 4, together with the $\varepsilon_{1}$ 
values (strain from creep tests at $0 \mathrm{~min}$ ) from Table 1 . It shows that for each creep condition, the instantaneous elastic strain $\varepsilon_{\mathrm{i}}$ compares well with the $\varepsilon_{\mathrm{e}}$ value (within $<1 \%$ difference). This indicates that the elastic strain was fully recovered upon load removal. Considering that no damage from the maximum $(24 \mathrm{~h})$ exposure to the $590 \mathrm{MPa}$ creep condition was found in terms of fiber topography, ${ }^{6}$ it may be concluded that there was no creep-induced fracture in the fibers for the creep stress conditions used.

\section{Stress rupture testing}

To determine the fiber failure properties, a higher creep stress was applied to polyamide 6,6 yarn. Since the breaking strength of polyamide 6,6 fiber is 700-900 MPa, a $665 \mathrm{MPa}$ creep stress (value restricted by the stretching rig) was adopted for rupture testing. Annealed fiber samples were stretched to break and the results are shown in Figure 5. Again, three samples were tested for repeatability purposes. As samples approached the Stage III region (Figure 1), the creep strain rate and probability of fiber fracture progressively increased and only one sample survived to $3 \mathrm{~h}$. Thus in Figure 5, data were available for two runs monitored up to $2 \mathrm{~h}$, and one run up to $3 \mathrm{~h}$. The yield creep strain was found to be $\sim 18 \%$, and this was reached after $\sim 2 \mathrm{~h}$ of stretching. Since Eq. (1) is not applicable to creep data beyond the yield point, the curve-fit is limited to the strain-time data below $18 \%$, and parameter values are listed in Figure 5.

\section{Predicting the 'true' elastic modulus}

The instantaneous elastic strain $\varepsilon_{\mathrm{i}}$ in Eq. (1) is a predicted value which cannot be measured. Thus a linear relationship between $\varepsilon_{\mathrm{i}}$ and stress $\sigma$ could enable the 'true' modulus of polyamide 6,6 fiber to be determined. As stated in the Introduction section, creep-strain data from both the current study and literature ${ }^{15,39}$ were considered. By using Eq. (1), the relationship between $\varepsilon_{1}$ and $\sigma$ could be constructed and is shown in Figure 6. The gradient from linear regression gives a true modulus value of $4.61 \mathrm{GPa}$. The scatter in data points may, at least in part, be attributed to differences in the microstructural characteristics (e.g. variations in crystallinity) between polyamide 6,6 fibers used in the current study and previous work. ${ }^{15,39}$ Variations in test conditions (temperature, humidity) would also be expected to contribute towards discrepancies between the three data sources. For the most influential data in Figure 6 however (Ref. 39 and current work), ambient conditions in Ref. 39 (19.5-21. $0^{\circ} \mathrm{C}$ and $\left.25-35 \% \mathrm{RH}\right)$ were similar to those of the current study. Acquisition of data from Ref. 15 for use in Eq. (1) has been described in previous work. ${ }^{16}$ The Ref. 15 data correspond to anhydrous fiber at $25^{\circ} \mathrm{C}$, but these conditions appear to have little effect in Figure 6, since the stressstrain values are relatively low. The dashed lines in Figure 6 are estimated 'worst case' gradients on both sides of the linear fit with intercepts set at zero, and these give values of $4.07 \mathrm{GPa}$ and $4.91 \mathrm{GPa}$. This provides an indication of the uncertainty, giving the true modulus as $4.6 \pm 0.4 \mathrm{GPa}$.

\section{Linear viscoelasticity}

Creep strain isochrones (Figure 2) for $1 \mathrm{~min}, 1 \mathrm{~h}$, and $24 \mathrm{~h}$ were produced from the curve fits in Figure 3(a), and results are shown in Figure 7. Although there is some scatter in data points, it is clear that the gradient values (from linear regression) decrease with the increase in creep duration, indicating that polyamide 6,6 fiber shows approximate linear viscoelastic performance under creep deformation at high stress values, i.e. 330-590 MPa. This corresponds with the creep behavior below 50 MPa stress. ${ }^{15,16}$

The shift factor $\alpha_{c}$ (for each creep stress value) can be determined using Eq. (3) from curve-fits as shown in Figures 3 and 5. With the $330 \mathrm{MPa}$ creep strain data set as a reference, the resulting data are 
plotted in Figure 8 which fit well to a linear trend. Shift parameter $\alpha_{c}$ values in Figure 8 were applied to the single creep runs. The resulting normalized creep strain data in Figure 9, from $330 \mathrm{MPa}$ to 590 $\mathrm{MPa}$, show a good fit, as most of the shifted data points fall within the scatter area of the $330 \mathrm{MPa}$ creep condition. These results show linear viscoelastic characteristics up to $590 \mathrm{MPa}$ creep stress. Of particular interest in Figure 9, is that approximate linear viscoelastic behavior is observed with the $665 \mathrm{MPa}$ creep data below $1 \mathrm{~h}$, as highlighted by the broken lines. It is clear that the rapid growth in creep rate (Stage III), started beyond $1 \mathrm{~h}$ of creep loading for the $665 \mathrm{MPa}$ runs (Figure 5), thus the yield creep strain can be considered as being further limited to $\sim 17.5 \%$. Therefore, it may be concluded that creep behavior of polyamide 6,6 fiber shows linear viscoelastic characteristics below the yield strain $(\sim 17.5 \%)$.

Since fiber rupture occurred at $665 \mathrm{MPa}$ stress, recovery runs up to $590 \mathrm{MPa}$ stress were used to investigate linear viscoelastic recovery. The same procedures as described earlier were used to determine the $\alpha_{\mathrm{r}}$ value for each recovery condition, and results are shown in Figure 10. Again, a linear trend can be fitted between $\alpha_{\mathrm{r}}$ and applied stress. Recovery strain-time curves as shown in Figure 3(b), were shifted through $\alpha_{\mathrm{r}}$, and normalized results are shown in Figure 11. The viscoelastic recovery of polyamide 6,6 fiber generally aligns with the $330 \mathrm{MPa}$ recovery strain, though there is more scatter of data compared with Figure 9, for reasons associated with the measurements in Figure 3(b). Despite the data scatter, the recovery behavior indicates approximate linear viscoelasticity.

These results indicate that polyamide 6,6 fiber shows approximately linear viscoelastic behavior for creep and recovery, which in turn makes the linear superposition principle applicable. ${ }^{46}$ This compares well with other findings, in that while the WLF equation has predicted a non-linear relationship between temperature and the temperature-shift factor for polymeric materials, a linear relationship was obtained for polyamide 6,6 material in terms of long-term creep ( $<50 \mathrm{MPa}$ stress), ${ }^{15}$ stress relaxation, ${ }^{33,35}$ and dynamic tensile modulus ${ }^{33}$ performance. Since the TSSP shares the same free volume theory with the TTSP, speculation can be made that $\log \alpha_{\sigma}$ may also demonstrate linear behavior with stress values. This is further investigated below.

\section{Application of the time-stress superposition principle}

By using the TSSP, single step short-term ( $24 \mathrm{~h}$ ) creep strain-time data as shown in Figure 3(a), could be superposed. Since temperature and humidity for all the creep strain measurements were controlled to be under the same conditions, the $330 \mathrm{MPa}$ creep strain was selected as the reference stress, $\sigma_{0}$. Figure 12 shows the corresponding stress shift factor plotted as $\left(\log \alpha_{\sigma}\right)$ versus $\left(\sigma-\sigma_{0}\right)$. Instead of an apparent non-linear relationship between $\log \alpha_{\sigma}$ and stress difference as predicted by Eq. (8), a linear regression was well fitted to the data points, giving a gradient of $0.024 \mathrm{MPa}^{-1}$. This enabled $\log \alpha_{\sigma}$ to be determined at $590 \mathrm{MPa}$ relative to $330 \mathrm{MPa}$, the resulting value being -6.2798 . Thus, for shifting strain data from $t$ to $t / \alpha_{\sigma}$, the viscoelastic creep using $590 \mathrm{MPa}$ would be $\sim 1,904,800$ times faster than a creep loading of $330 \mathrm{MPa}$, i.e. polyamide yarns subjected to $590 \mathrm{MPa}$ for $24 \mathrm{~h}$ would be equivalent to a $330 \mathrm{MPa}$ creep stress applied for $\sim 5200$ years.

Figure 13 shows the resulting master creep curve, obtained simply through a horizontal shift (i.e. from $t$ to $t / \alpha_{\sigma}$ ) of the creep stress curves in Figure 3(a). Eq. (1) was used for the curve fitting, and corresponding parameter values are also shown in Figure 13. As elastic strain is dependent on stress, the value of $\varepsilon_{1}$ for the master curve is equal to the reference creep stress, i.e. $7.956 \%$ (Table 1). It is clear that the master curve is well fitted by Eq. (1), which effectively shows the creep deformation at $330 \mathrm{MPa}$ over a vast timescale. 
The principle of linear TSSP in creep behavior as discussed above was also applied to the recovery results. Here, the recovery strain under $590 \mathrm{MPa}$ stress was set as the reference, and the same shift factor values in Figure 12 were applied to the recovery data in Figure 3(b) in a reversed order. The resulting recovery master curve is shown in Figure 14, which corresponds to load removal on yarns being subjected to $330 \mathrm{MPa}$ creep stress for $\sim 4.56 \times 10^{7} \mathrm{~h}$, as represented in Figure 13. Clearly, this is an impractical duration; however, the results do demonstrate long-term linear viscoelastic recovery. Eq. (2) was used for curve-fitting, which is shown in Figure 14, together with the parameter values. Again, viscoelastic flow effects are predicted to be negligible.

\section{CONCLUSIONS}

To understand further the mechanisms responsible for generating prestress within VPPMCs, the elastic and viscoelastic behavior of polyamide 6,6 fiber under high stress conditions were investigated in this work. The main findings were:

(i) Creep and recovery tests showed that elastic strains were fully recovered on load removal for all the $24 \mathrm{~h}$ creep stress values up to $590 \mathrm{MPa}$; this indicates there was no creep-induced damage. Since viscous flow was found to be negligible for all creep conditions, VPPMC prestressing mechanisms would not be limited by this.

(ii) The yield creep strain was determined from creep rupture tests, in which fiber yarns were subjected to $665 \mathrm{MPa}$ creep stress. Yield strain was achieved after $2 \mathrm{~h}$, which rapidly led to fracture beyond $\sim 18 \%$ creep strain.

(iii) The 'true' modulus of the fiber was found to be $4.6 \pm 0.4 \mathrm{GPa}$; this was achieved through the use of the Weibull-based function from which the pure elastic strain could be determined.

(iv) The fiber showed approximate linear viscoelastic characteristics at large creep deformations, from 330 to $590 \mathrm{MPa}$. This enabled the linear TSSP to be implemented; i.e. a linear relationship between the stress shift factor, $\log \alpha_{\sigma}$, and stress was obtained. The resulting master creep curve enabled the creep behavior at $330 \mathrm{MPa}$ to be predicted over a large timescale.

(v) The linear TSSP obtained from creep could be applied to corresponding recovery strain data. A master recovery curve was developed through the stress shift factor, $\log \alpha_{\sigma}$, this being equivalent to load removal in the master creep curve, in which yarns would have been stretched with $330 \mathrm{MPa}$ creep stress for $\sim 4.56 \times 10^{7} \mathrm{~h}$. Although this is impractical, it does demonstrate long-term linear viscoelastic recovery.

In the broader context, we hope our findings will be of interest to all those involved with long-term load-bearing applications using polyamide materials.

\section{ACKNOWLEDGEMENTS}

One of the authors (B.W.) would like to thank the China Scholarship Council (CSC) for financial support and a PhD degree fee waiver from the School of Engineering. Special thanks go to Garry Robinson from the School of Engineering for technical support. 


\section{REFERENCES}

1. Lakes, R. S. Viscoelastic solids. CRC press: Washington, 1998.

2. Fancey, K. S. Mater. Sci. Eng. A 2000, 279, 36.

3. Fazal, A., Fancey, K. S. Polym. Compos. 2014, 35, 931.

4. Wang, B., Fancey, K. S. Mater. Lett. 2015, 158, 108.

5. Fancey, K. S. J. Reinf. Plast. Comp. 2016, 35, 1290.

6. Wang, B.; Fancey, K. S. Compos. Part B-Eng. 2016, 87, 336.

7. Lewin, M. Handbook of fiber chemistry. CRC Press: New York, 2006.

8. Peterlin, A. J. Appl. Phys. 1977, 48, 4099.

9. Peterlin, A. Colloid Polym. Sci. 1975, 253, 809.

10. Peterlin, A. J. Mater. Sci. 1971, 6, 490.

11. Peterlin, A. J. Macromol. Sci. B. 1973, 8, 83.

12. Marcellan, A.; Bunsell, A. R.; Laiarinandrasana, L.; Piques, R. Polymer. 2006, 47, 367.

13. Prevorsek, D.; Harget, P.; Sharma, R.; Reimschuessel, A. J. Macromol. Sci. B. 1973, 8, 127.

14. Bukošek, V.; Prevoršek, D. C. Int. J. Polym. Mater. 2000, 47, 569.

15. Howard, W. H.; Williams, M. L. Text. Res. J. 1963, 33, 689.

16. Fancey, K. S. J. Polym. Eng. 2001, 21, 489.

17. Starkova, O.; Yang, J.; Zhang, Z. Compos. Sci. Technol. 2007, 67, 2691.

18. Fancey, K. S. J. Mater. Sci. 2005, 40, 4827.

19. ASTM D638-02A. Standard test method for tensile properties of plastics. ASTM International: West Conshohocken; 2002.

20. Raisch, S. R.; Möginger, B. Polym. Test. 2010, 29, 265.

21. Richeton, J.; Schlatter, G.; Vecchio, K. S.; Rémond, Y.; Ahzi, S. Polymer. 2005, 46, 8194.

22. MatWeb Materials information database. http://www.matweb.com/ (accessed Feb 2015).

23. Courtney, T. H. Mechanical behaviour of materials. McGraw-Hill Publishing Company: New York, 1990.

24. Bernstein, B.; Shokooh, A. J. Rheol. 1980, 24, 189.

25. Ferry, J. D. Viscoelastic properties of polymers. John Wiley \& Sons: New York, 1980.

26. Luo, W.; Yang, T.; An, Q. Acta Mech. Solida Sin. 2001, 14, 195.

27. Hunt, D. G.; Darlington, M. W. Polymer 1979, 20, 241.

28. Jazouli, S.; Luo, W.; Bremand, F.; Vu-Khanh, T. Polym. Test. 2005, 24, 463.

29. Schoeberle, B.; Wendlandt, M.; Hierold, C. Sensor. Actuat. A-Phys. 2008, 142, 242.

30. Beijer, J. G. J.; Spoormaker, J. L. Polymer. 2000, 41, 5443.

31. Tajvidi, M.; Falk, R. H.; Hermanson, J. C. J. Appl. Polym. Sci. 2005, 97, 1995.

32. Chevali, V. S.; Dean, D. R.; Janowski, G. M. Compos. Part A-Appl. S. 2009, 40, 870.

33. Dunell, B.; Joanes, A. A.; Rye, R. J. Colloid Sci. 1960, 15, 193. 
34. Zhou, S. M.; Tashiro, K.; Ii, T. J. Polym. Sci. Polym. Phys. 2001, 39, 1638.

35. Murayama, T.; Dumbleton, J. H.; Williams, M. L. J. Macromol. Sci. B. 1967, 1, 1.

36. Drozdov, A. D. Math. Comput. Model. 1997, 25, 45.

37. Williams, M. L.; Bender, M. F. J. Appl. Phys. 1965, 36, 3044.

38. Fancey, K. S. J. Adv. Mater-Covina. 2005, 37, 21.

39. Pang, J. W. C.; Fancey, K. S. Mat. Sci. Eng. A-Struct. 2006, 431, 100.

40. Wang, B. Viscoelastically prestressed composites: towards process optimisation and application to morphing structures. Ph.D. Thesis, University of Hull, Hull, UK, 2016.

41. Fancey, K. S. J. Reinf. Plast. Comp. 2000, 19, 1251.

42. Babatope, B.; Isaac, D. H. Polymer. 1992, 33, 1664.

43. Fancey, K. S. Compos. Part B-Eng. 2010, 41, 454.

44. Zhang, Z.; Yang, J.-L.; Friedrich, K. Polymer. 2004, 45, 3481.

45. ASTM D 2990-01. Standard test methods for tensile, compressive, and flexural creep and creep-rupture of plastics. ASTM International: West Conshohocken; 2001.

46. Findley, W. N.; Davis, F. A. Creep and relaxation of nonlinear viscoelastic materials. Courier Corporation; 2013.

47. Crawford, R. J. Plastics engineering ( $3^{\text {rd }}$ Ed). Butterworth-Heinemann: London, 1998.

48. Williams, M. L.; Landel, R. F.; Ferry, J. D. J. Am. Chem Soc. 1955, 77, 3701.

49. Doolittle, A. K. J. Appl. Phys. 1951, 22, 1471.

50. O'Shaughnessy, M. T. Text. Res. J. 1948, 18, 263.

51. Ferry, J. D.; Stratton, R. A. Kolloid-Zeitschrift. 1960, 171, 107.

52. Fancey, K. S.; Fazal, A. Polym. Compos. 2015, 37, 2092. 
Table 1 Summary of the creep and recovery parameter values from data in Figure 3 using Eqs. (1) and (2); $r$ is the correlation coefficient.

\begin{tabular}{|c|c|c|c|c|c|}
\hline \multirow{2}{*}{$\begin{array}{l}24 \mathrm{~h} \text { applied } \\
\text { stress }(\mathrm{MPa})\end{array}$} & \multirow[b]{2}{*}{$\varepsilon_{\mathrm{c}}(\%)$} & \multicolumn{3}{|c|}{ Creep parameters } & \multirow[b]{2}{*}{$r$} \\
\hline & & $\beta_{\mathrm{c}}$ & $\eta_{\mathrm{c}}(\mathrm{h})$ & $\varepsilon_{\mathrm{i}}(\%)$ & \\
\hline $330^{*}$ & 3.538 & 0.2245 & 0.1428 & 7.956 & 0.9729 \\
\hline 395 & 3.665 & 0.2614 & 0.1856 & 9.223 & 0.9707 \\
\hline $460^{*}$ & 4.317 & 0.2048 & 0.1889 & 10.181 & 0.9939 \\
\hline 525 & 4.148 & 0.2419 & 0.1418 & 11.049 & 0.9926 \\
\hline $590^{*}$ & 5.044 & 0.2830 & 0.4256 & 12.141 & 0.9957 \\
\hline \multirow{2}{*}{$\begin{array}{l}24 \mathrm{~h} \text { applied } \\
\text { stress }(\mathrm{MPa})\end{array}$} & & \multicolumn{3}{|c|}{ Recovery parameters } & \\
\hline & $\varepsilon_{\mathrm{r}}(\%)$ & $\beta_{\mathrm{r}}$ & $\eta_{\mathrm{r}}(\mathrm{h})$ & $\varepsilon_{\mathrm{f}}(\%)$ & $r$ \\
\hline $330^{*}$ & 3.052 & 0.1270 & 1155 & $<10^{-9}$ & 0.9651 \\
\hline 395 & 3.800 & 0.1068 & 7175 & $<10^{-9}$ & 0.9795 \\
\hline $460^{*}$ & 4.361 & 0.1056 & 9637 & $<10^{-4}$ & 0.9865 \\
\hline 525 & 3.956 & 0.1734 & 77400 & $<10^{-4}$ & 0.9878 \\
\hline $590^{*}$ & 4.621 & 0.2062 & 150468 & $<10^{-5}$ & 0.9853 \\
\hline
\end{tabular}




\section{FIGURE CAPTIONS}

Figure 1 Schematic of the creep and recovery characteristics of a polymeric material under a constant stress.

Figure 2 Schematic of stress-strain behavior for elastic and viscoelastic materials at two values of elapsed time $t^{\prime}$ and $t^{\prime \prime}$. Redrawn from Ref. 47.

Figure 3 Strain-time data for (a) $24 \mathrm{~h}$ creep and (b) recovery at the five stress values with curvefits from Eqs. (1) and (2). For each stress value: three runs were performed, as represented by the different symbols; individual data points from all three runs were used to produce the curve fit.

Figure 4 Plot of instantaneous strain $\varepsilon_{\mathrm{i}}$ and elastic recovery strain $\varepsilon_{\mathrm{e}}$ values at each creep condition. These values were obtained from Eqs. (1) and (2).

Figure 5 Strain-time behavior of polyamide 6,6 fiber under 665 MPa creep stress. Dashed line shows the development of Stage III in creep behavior, which is the prelude to fiber failure.

Figure 6 Plot of elastic strain $\varepsilon_{1}$ versus creep stress $\sigma$, predicted from Eq. (1) using data from Table 1 and published work. The linear regression gives the modulus value of polyamide 6,6 fiber as $4.61 \mathrm{GPa}$. Dashed lines show 'worst case' gradients, indicating the uncertainty in the modulus result.

Figure 7 Creep strain isochrones for polyamide 6,6 fiber at $1 \mathrm{~min}, 1 \mathrm{~h}$ and $24 \mathrm{~h}$, respectively. Linear regression shows the trends.

Figure 8 Shift factor $\alpha_{\mathrm{c}}$ for each creep stress value, with $330 \mathrm{MPa}$ creep stress as the reference.

Figure 9 Strain-time relationships normalised to the $330 \mathrm{MPa}$ creep condition through shift factors $\alpha_{\mathrm{c}}$ from Figure 8.

Figure 10 Shift factor $\alpha_{\mathrm{r}}$ for each recovery curve; recovery strain from $330 \mathrm{MPa}$ creep is set as the reference.

Figure 11 Strain-time relationships after normalising to the $330 \mathrm{MPa}$ recovery condition through shift factors $\alpha_{\mathrm{r}}$, as shown in Figure 10.

Figure 12 Plot of the time-stress shift factor, $\alpha_{\sigma}$, as a function of stress difference, $\sigma-\sigma_{0}$. Reference creep stress, $\sigma_{0}$ is $330 \mathrm{MPa}$. The equation is from linear regression; $r$ is the correlation coefficient.

Figure 13 Master curve for creep strain versus time in polyamide 6,6 fiber, obtained from the TSSP, using data from Figure 3(a).

Figure 14 Recovery master curve obtained from the TSSP, using data from Figure 3(b). Applied shift factor values are those shown in Figure 12, but in reversed order. 


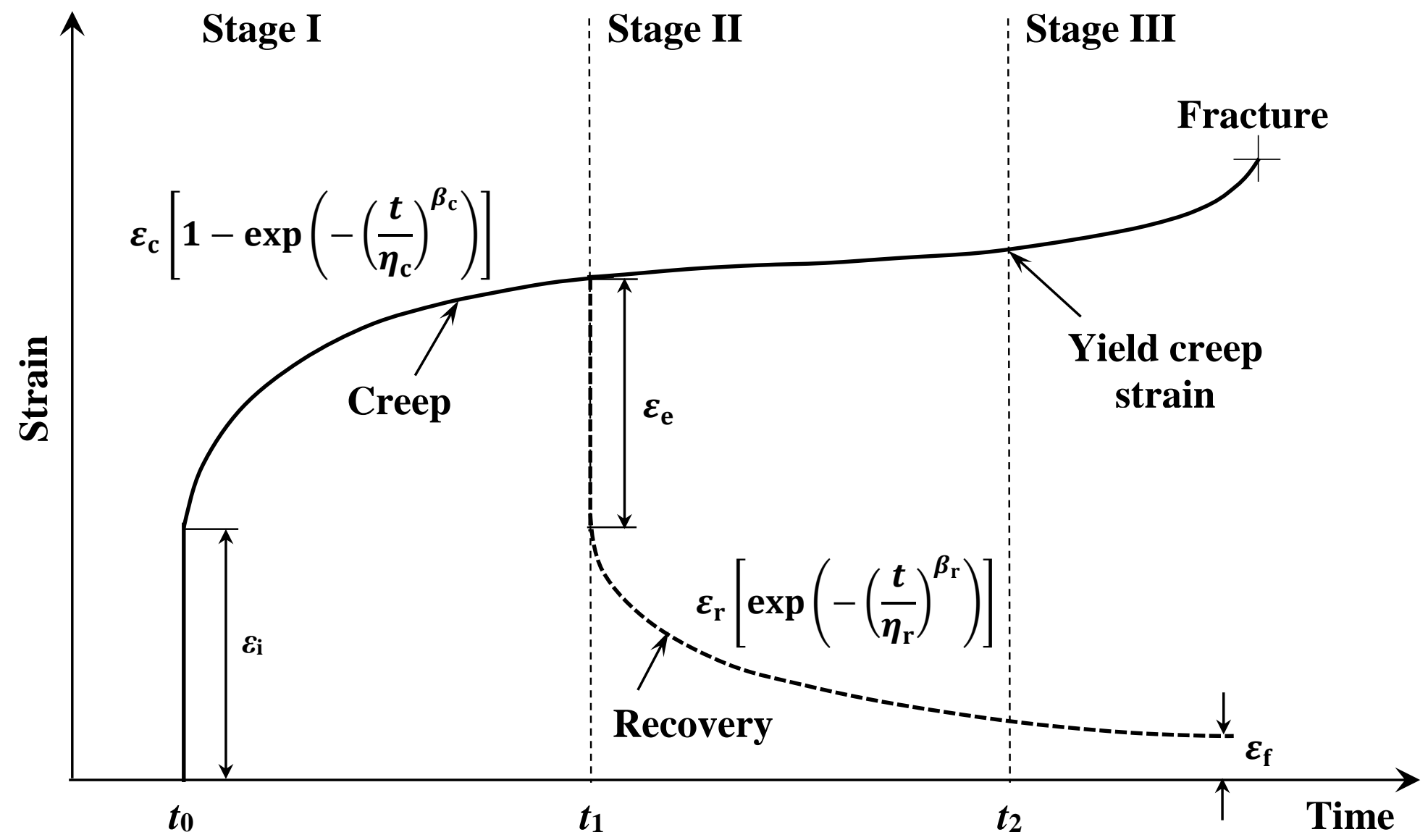

Figure 1 


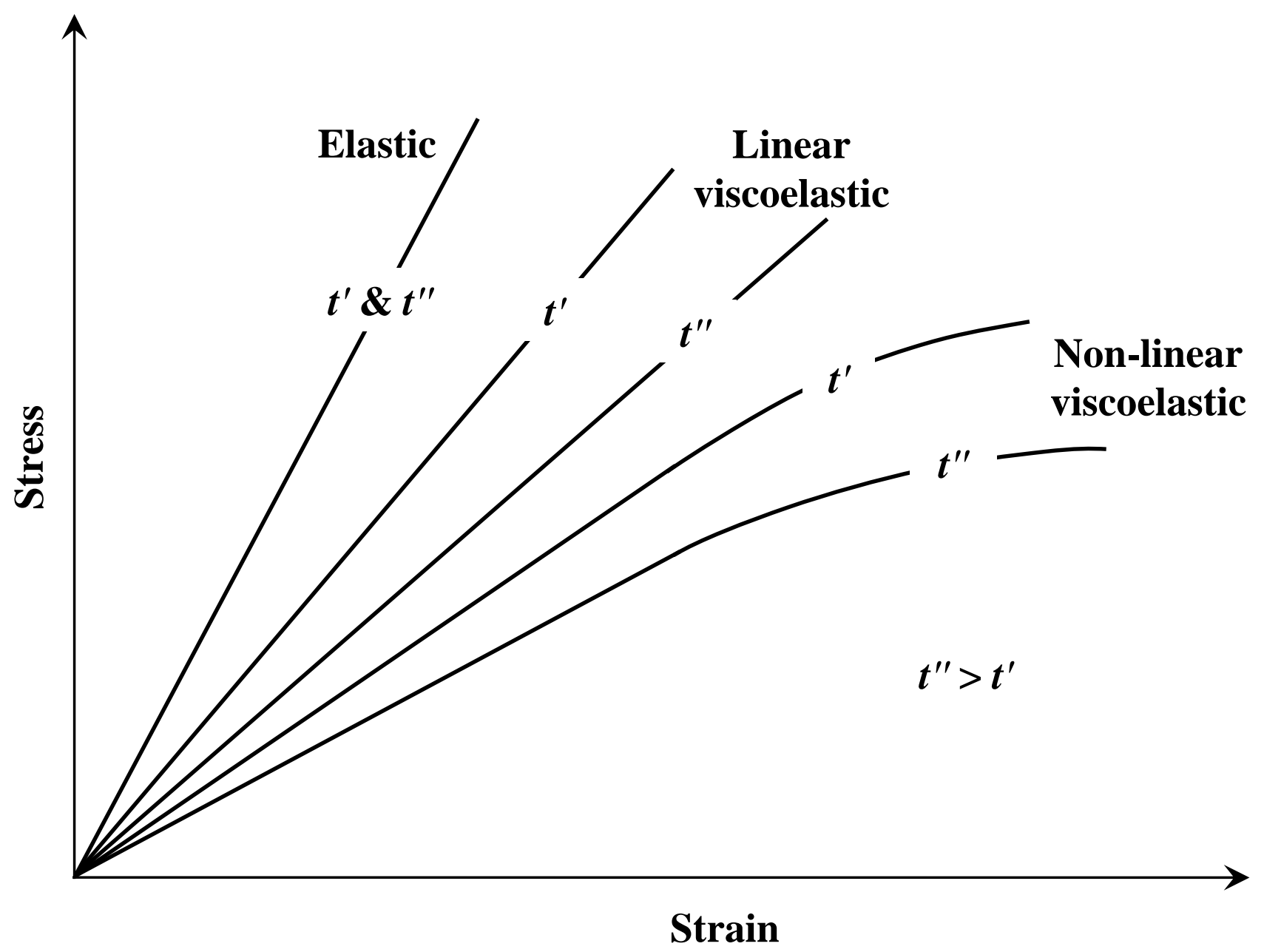

Figure 2 

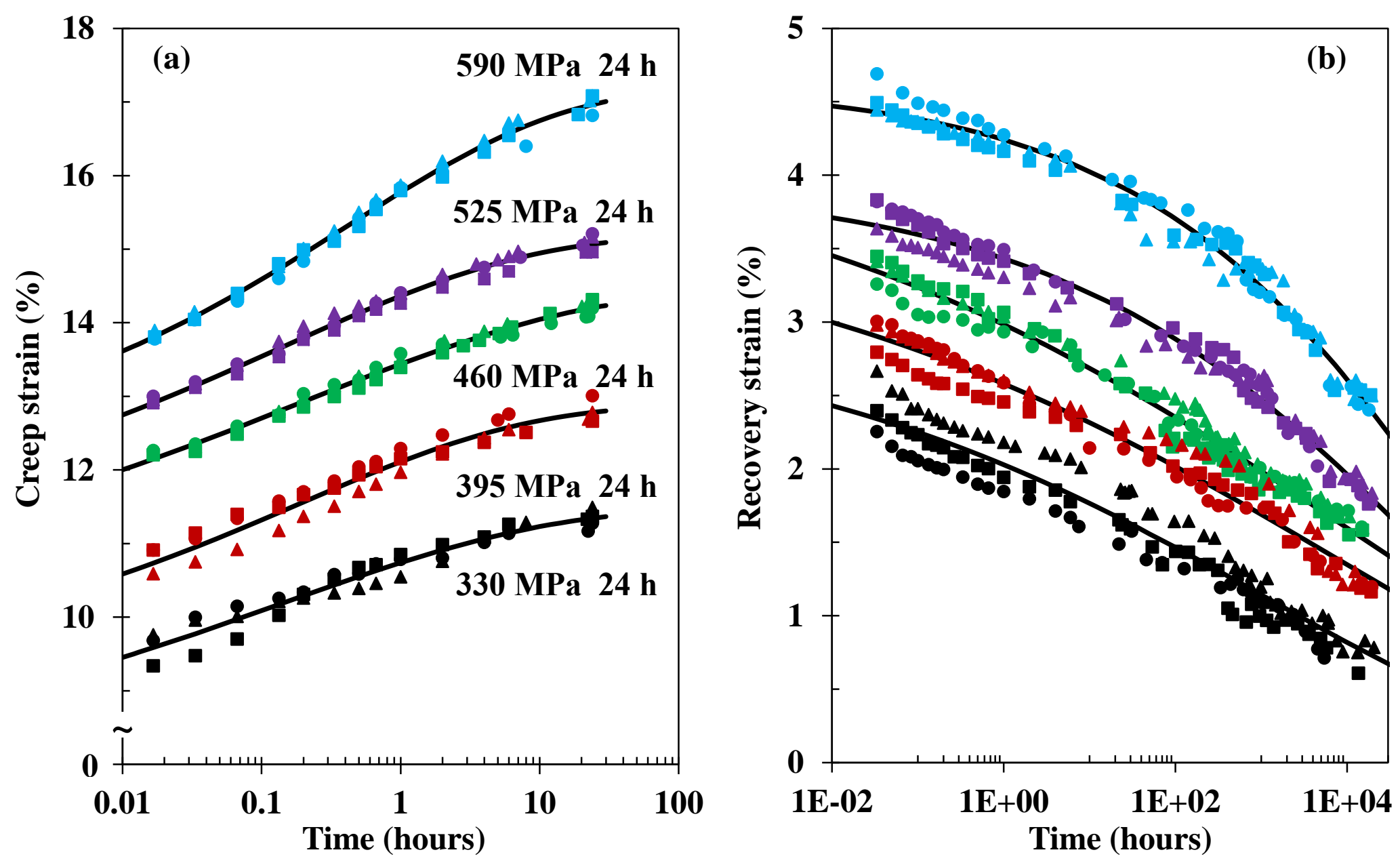


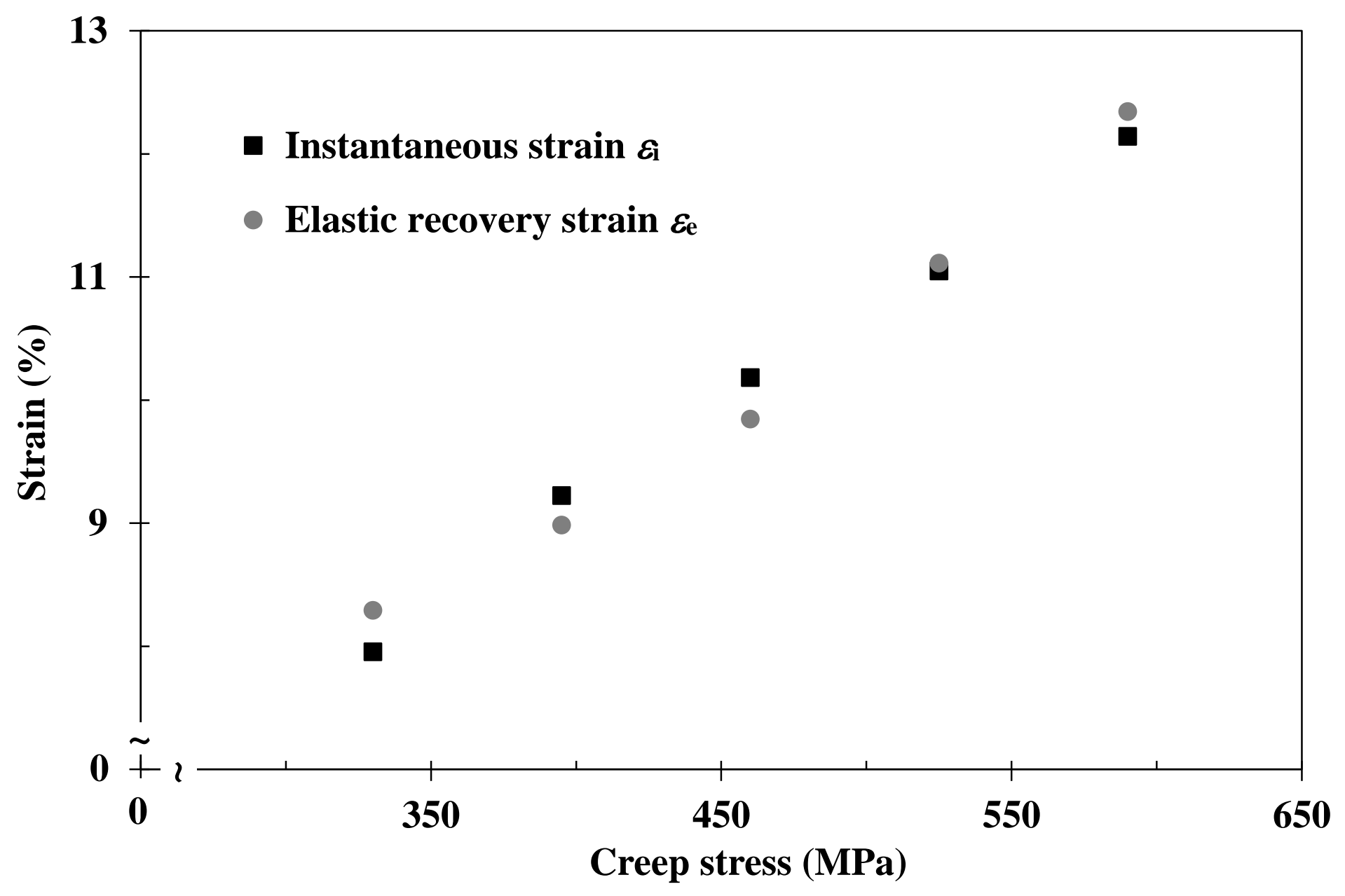

Figure 4 


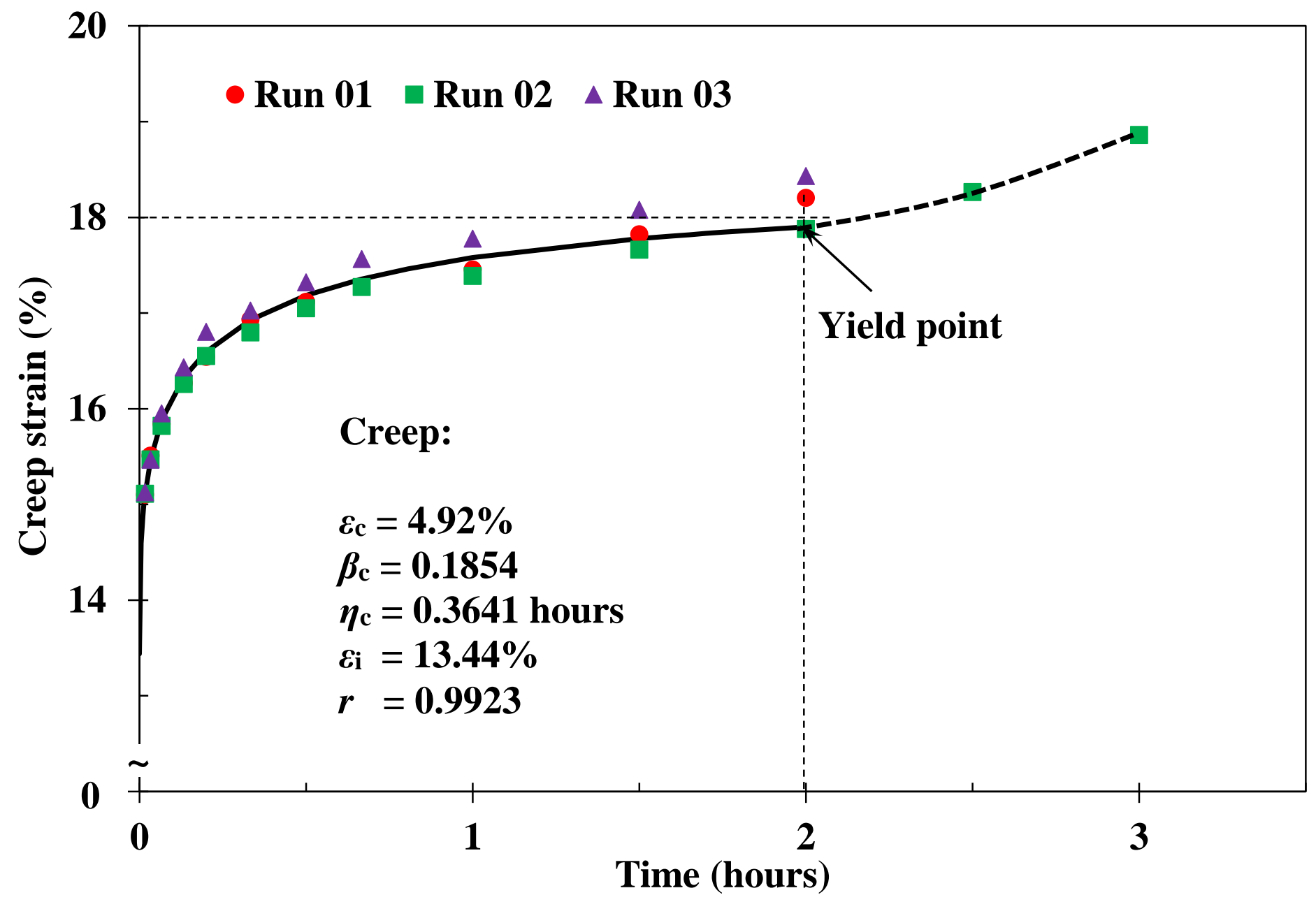

Figure 5 


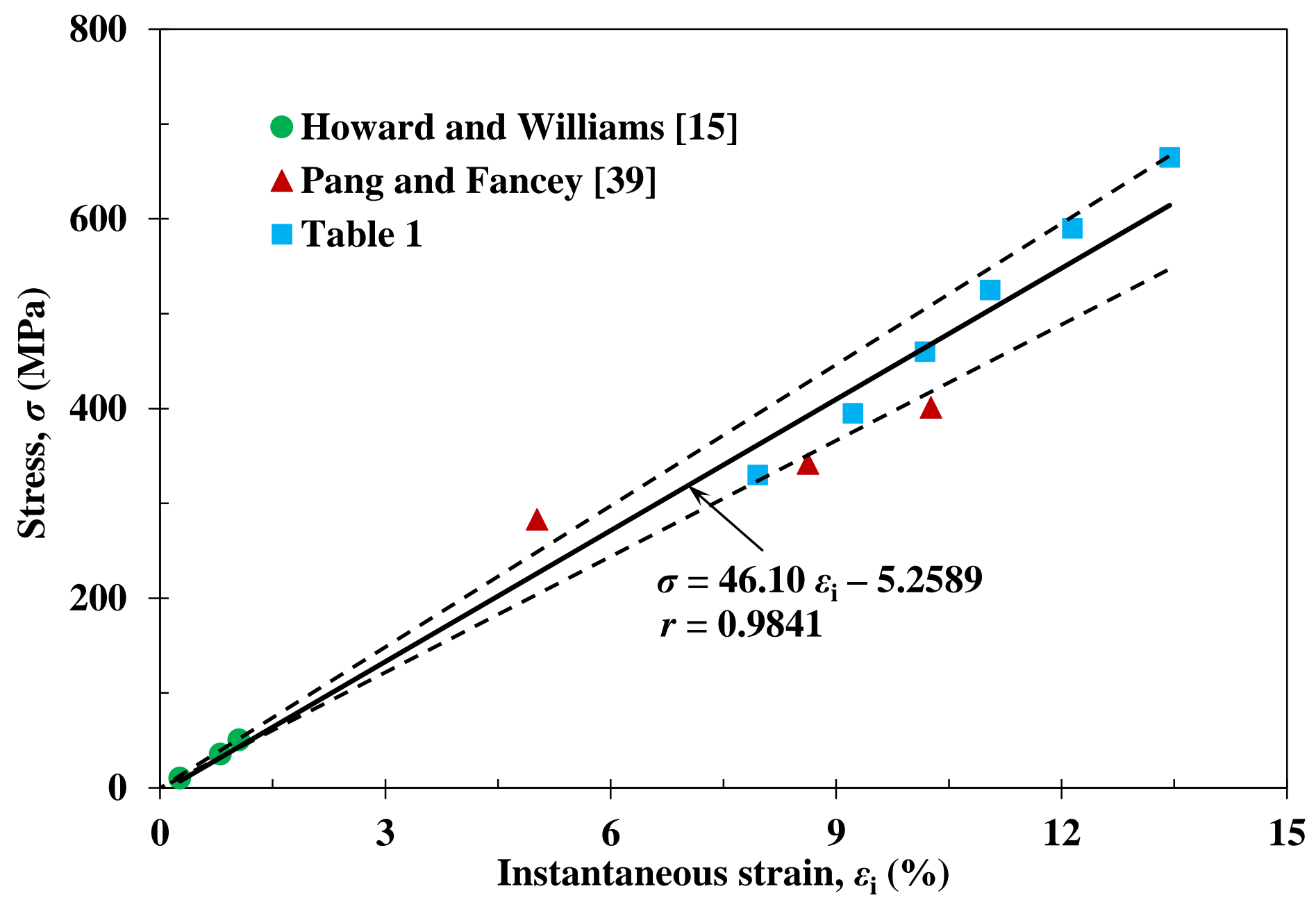

Figure 6 


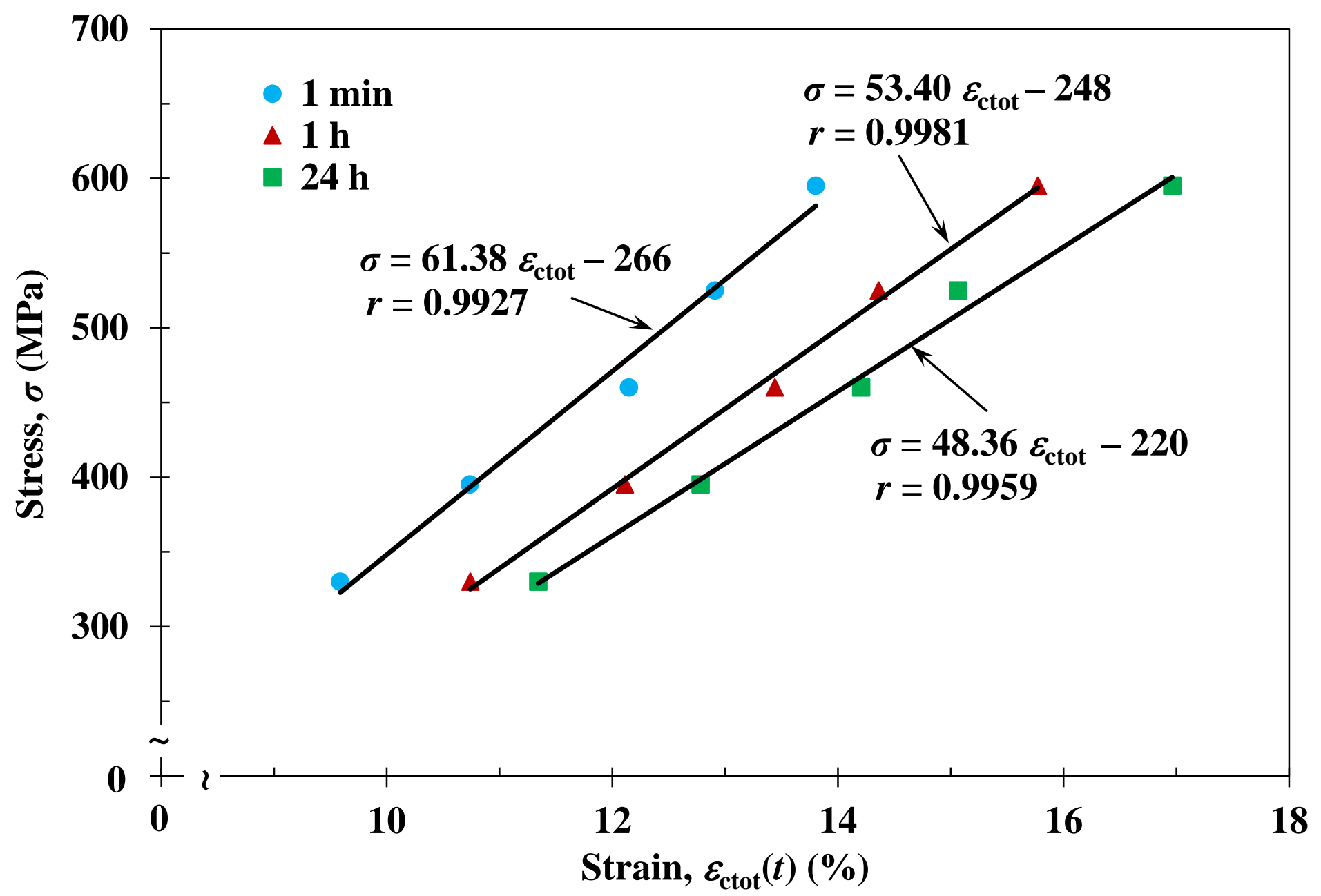

Figure 7 


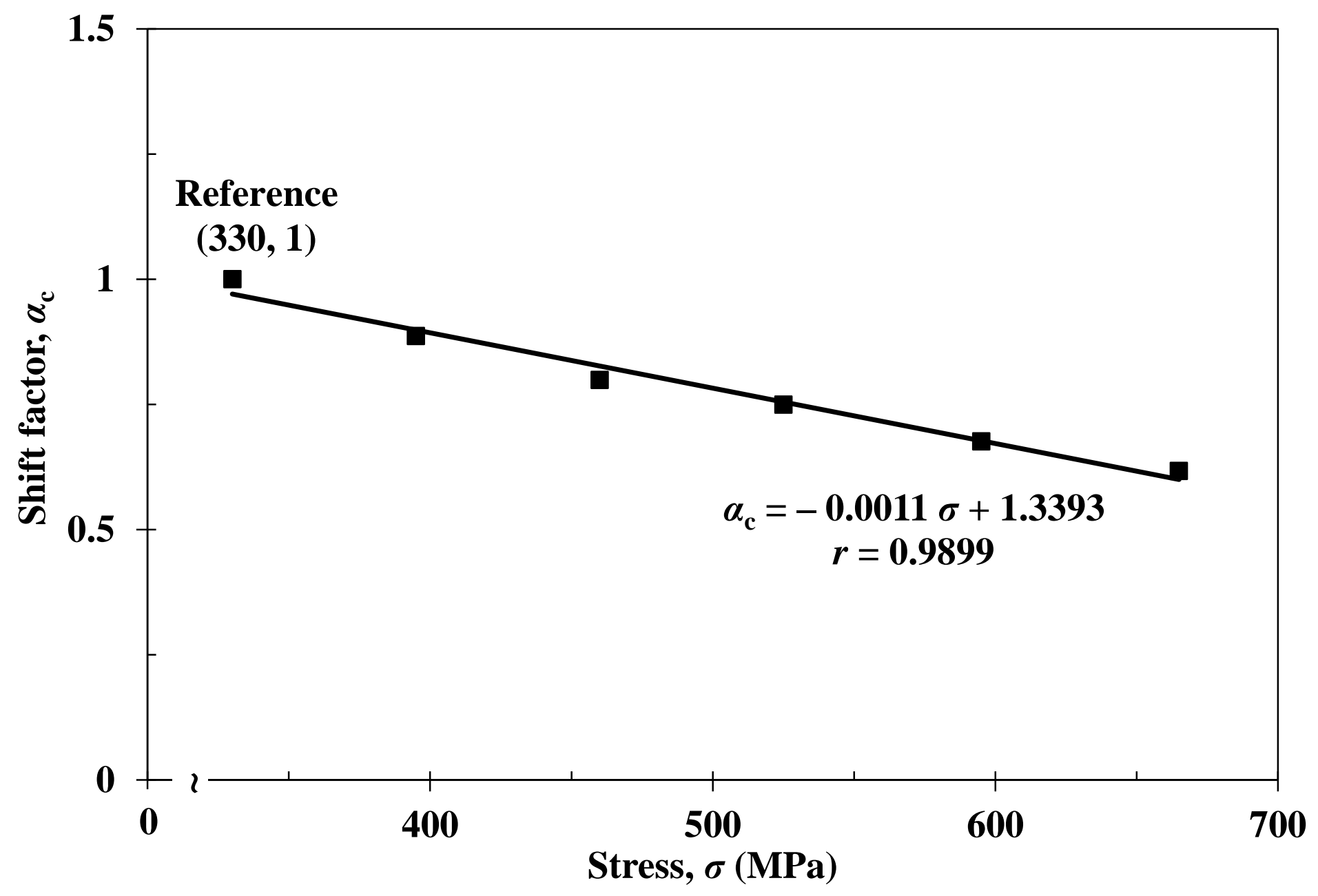

Figure 8 


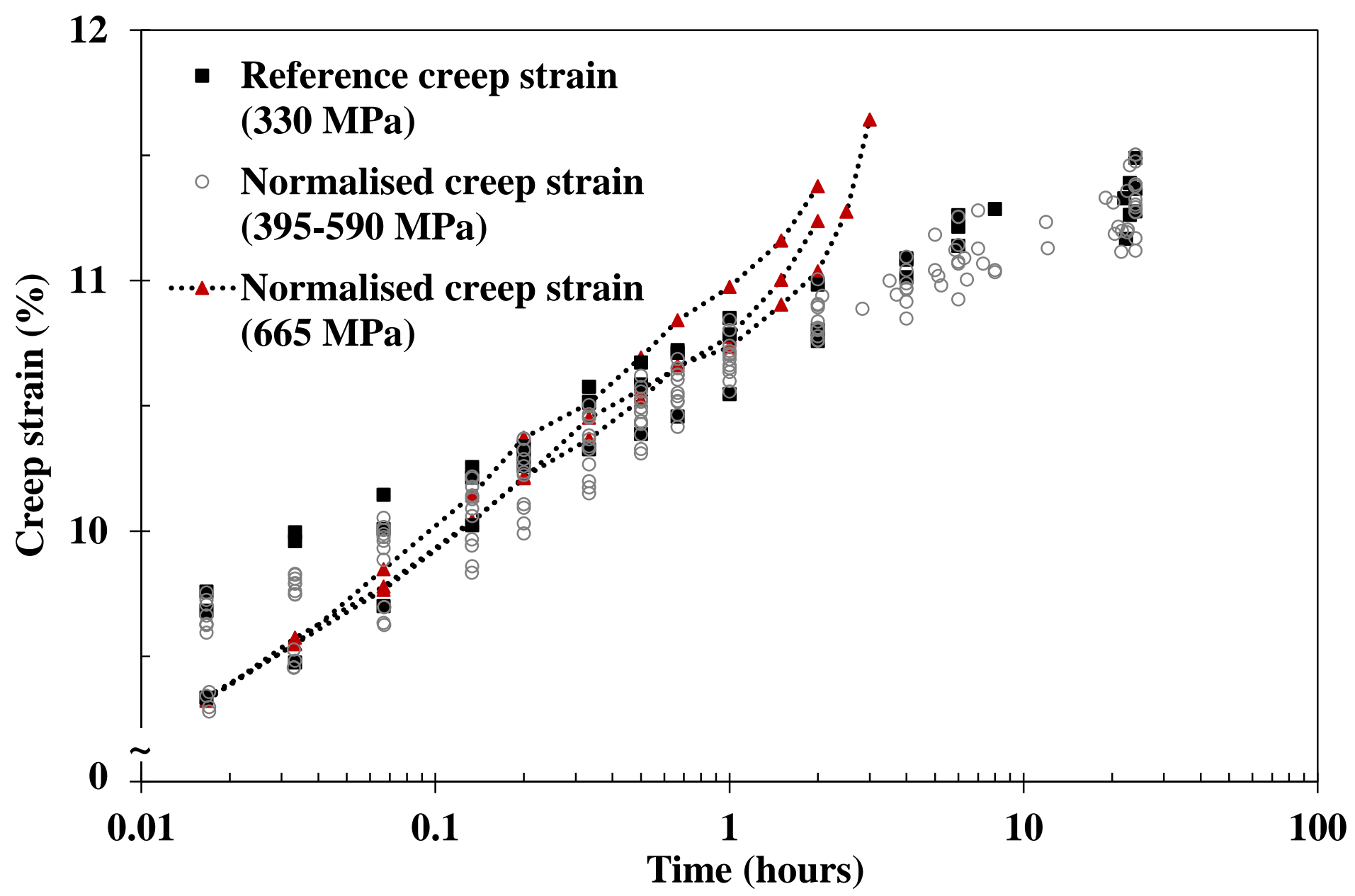

Figure 9 


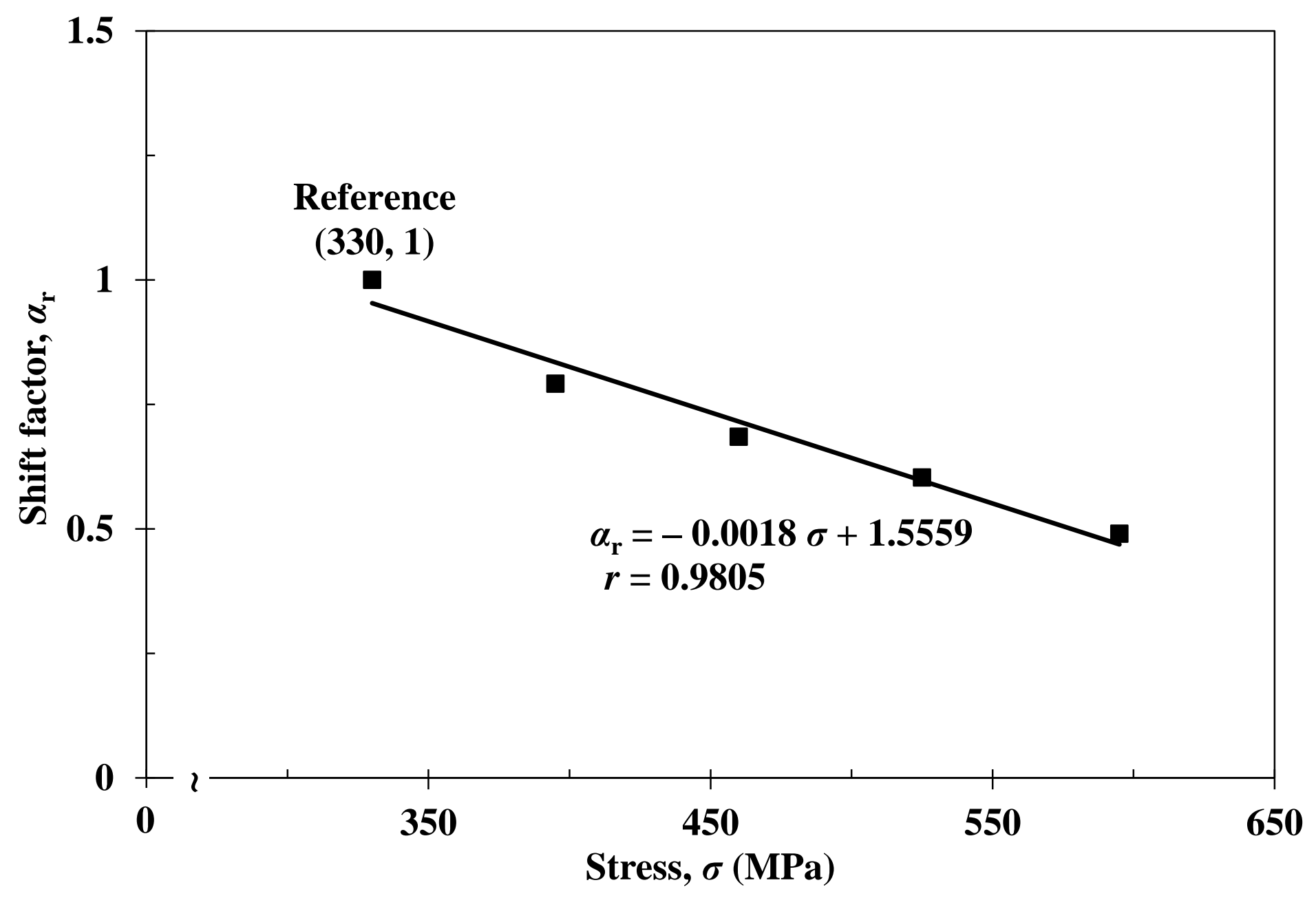

Figure 10 


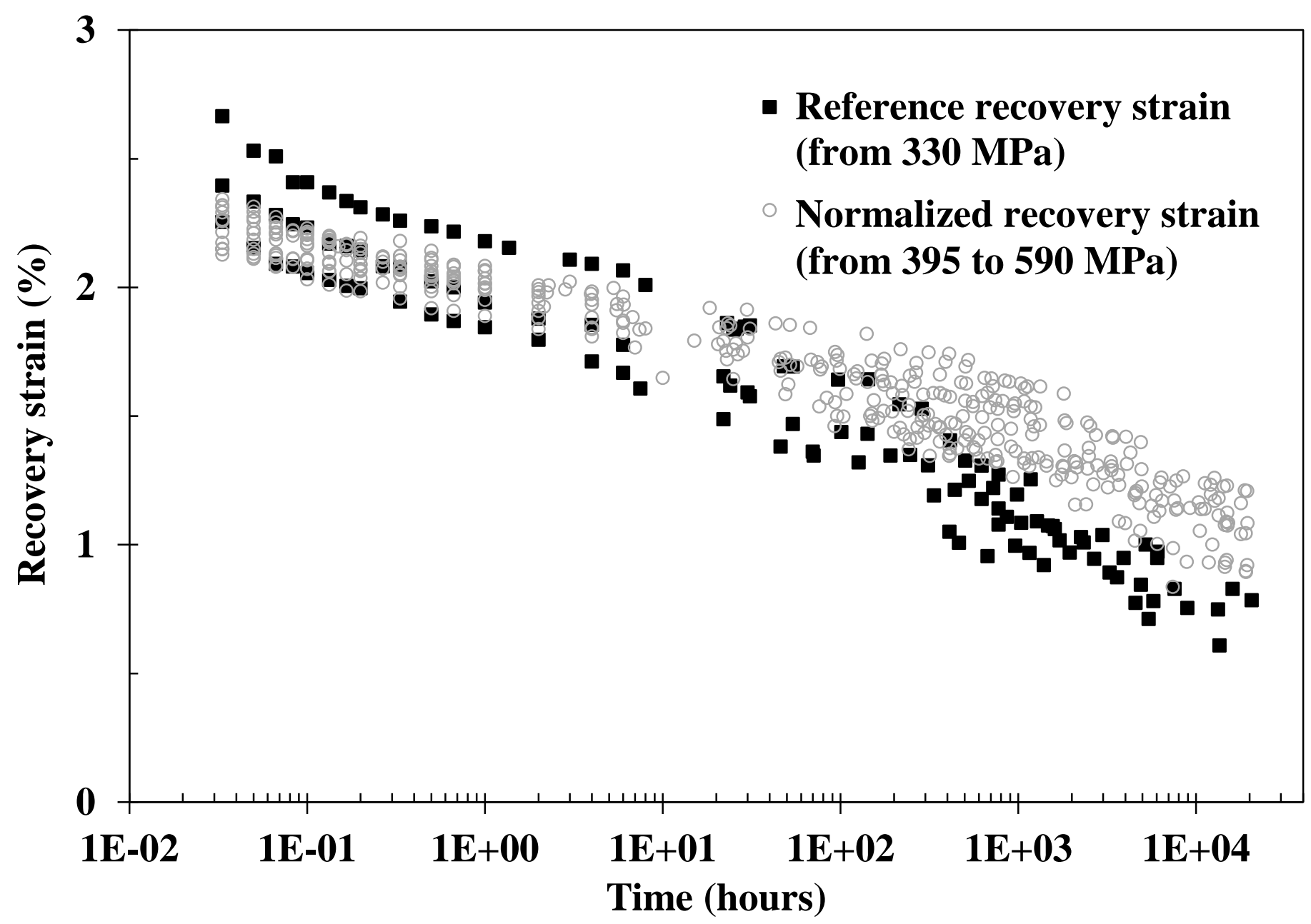

Figure 11 


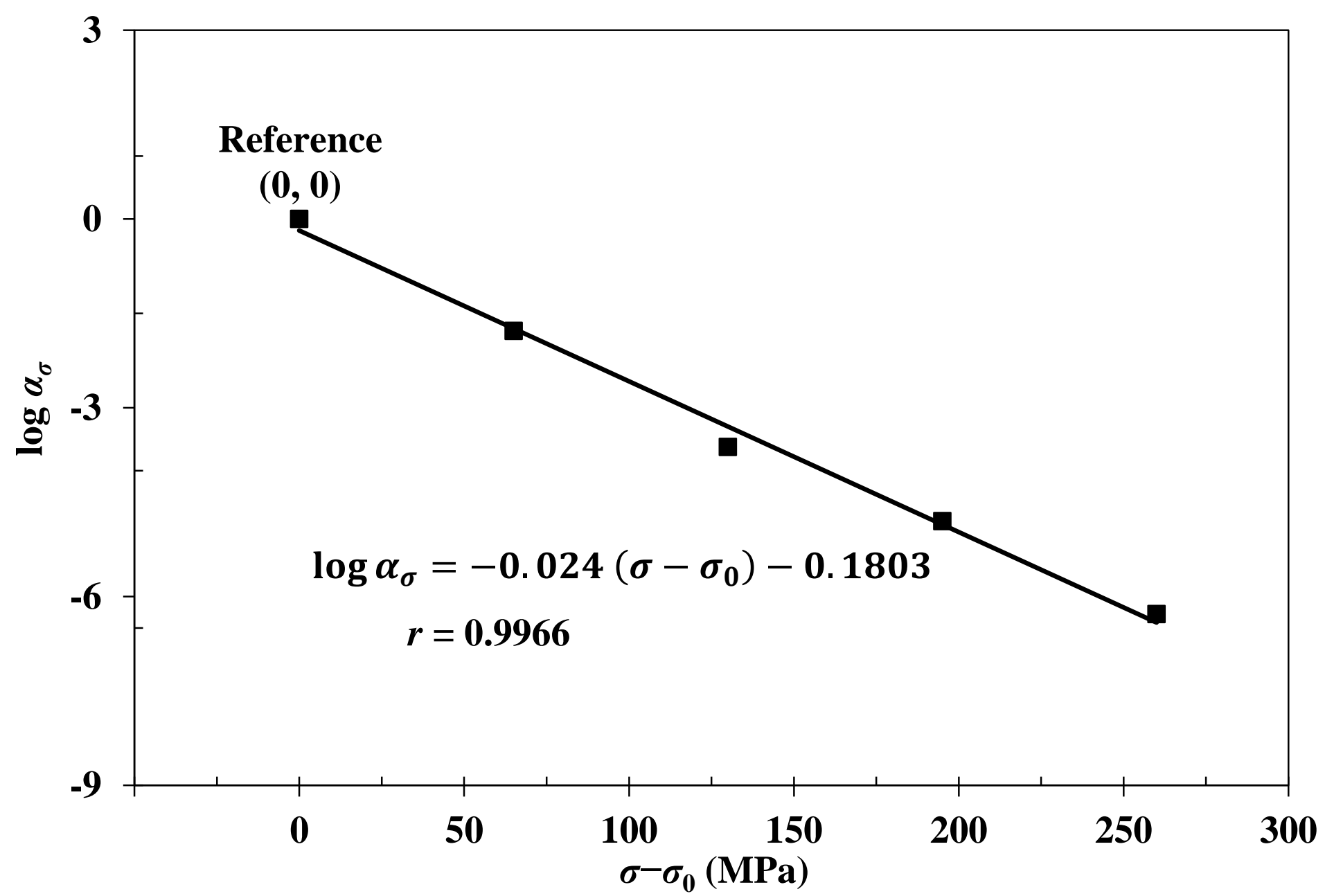

Figure 12 


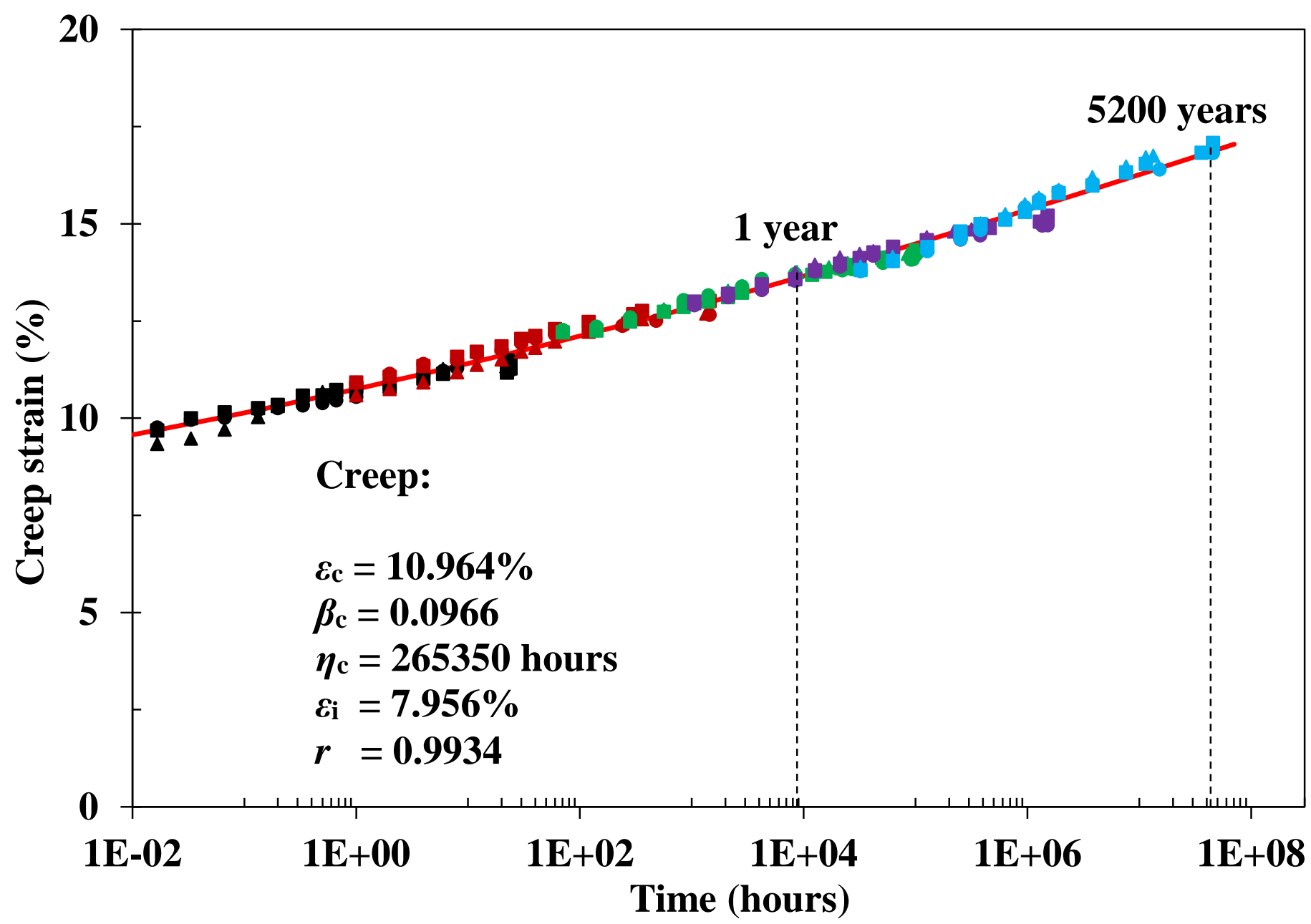

Figure 13 


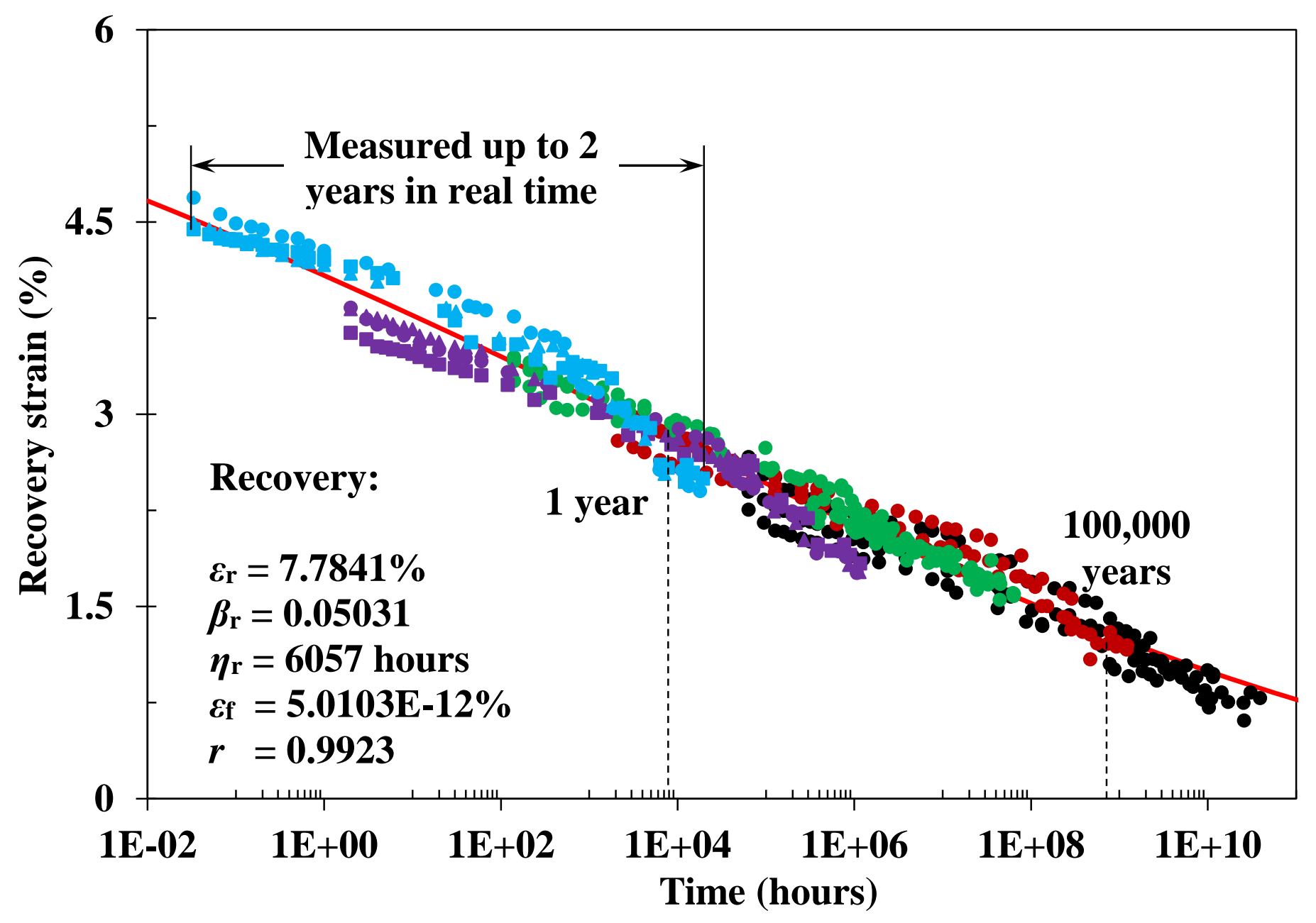

Figure 14 